\title{
Knowledge and Effects of Teenage Pregnancies Among the Adolescent Girls Between 13 and 19 Years at Mukono Parish Kanungu District - Uganda.
}

\section{Journal of Community Health and Behavioural Sciences@SJHR-Africa.}

\author{
Hubert Nkabura ${ }^{a}, 1,2$ \\ a Faculty of Clinical Medicine and Community Health, Medicare Health Professional's College, \\ Mengo, Kampala, Uganda
}

\begin{abstract}
Background:
Teenage pregnancy prevalence is at $25 \%, 16 \%$ of Ugandan women are married by the age of 15 years and $53 \%$ by the age of 18 years. Available information reveals that teenage pregnancies carry a higher health risk and girls under 15 years are five times more likely to die in childbirth than females in their twenties. An estimate of 6,000 teenagers dies annually from maternal related complications.

Methodology:

A descriptive cross-sectional study was conducted in February 2016 where a total of 100 respondents were selected from Mukono Parish residents' register using a simple random sampling technique. Data was collected using a pretested questionnaire.

Results:

$76 \%$ had prior knowledge about sex education whereas $24 \%$ had not. $42 \%$ got the information from the school a gesture that respondents took part in the classroom discussion about sexuality, $28 \%$ from newspapers -straight talk, $16 \%$ health worker, and $14 \%$ from their parents. $45 \%$ believed that school dropout is due to social effect of teenage pregnancy, $34 \%$ said that teen mother is more likely to have no or low qualifications and $9 \%$ said that child of a teen mother is more likely to abuse drugs, $12 \%$ don't know any of the social effects.

Conclusion and recommendations:

Teenagers in Uganda are informed about sex education. The government in conjunction with the development partners needs to include sex education in the school curriculum. The girl child needs to be educated on how to protect herself and avoid becoming a victim of teenage pregnancy. Parents should not shy away from educating their children about sex education while they are still young, by so doing the teens grow knowing the consequences of early pregnancy. Pregnant teenagers need to be encouraged to attend antenatal care as well as welcomed into society without stigmatization.
\end{abstract}

\section{Background}

Teenage is a critical stage in a person's life. It is a period in which physical, psychological and social changes take place in one's life. It starts from thirteen to nineteen years of age. Teenage is similar to adolescence which is defined by the World Health Organization (WHO) as a progression from secondary

\footnotetext{
${ }^{1}$ Corresponding author.

2E-mail: hubbyndik@gmail.com
} 
sexual characteristics (puberty) to sexual and reproductive maturity. It involves making major decisions about roles in life. It is as well a period in which preparations of activities for adulthood are undertaken (WHO, 2004).

During this period people become emotionally attracted to the opposite sex. Teenagers are conscious of their looks, personality, people with whom they associate, and activities that please them. Teenagers may rebel against parents, and their role models may be artists, actors, teachers, pop musicians, or other kinds of persons. They can also start involving in bad behaviour and subsequently have sexual experimentation as a result of peer pressure which leads to unwanted pregnancies (Rachel, 2009).

Teenage pregnancy is pregnancy in girls below the age of 20 years. It is one of the most devastating reproductive health challenges and has consequences not only for the individual girl but also for the community and country as a whole. One out of four girls aged $15-19$ years is already a mother or pregnant with her first child. Uganda has one of the highest adolescent pregnancy rates in Sub- Saharan Africa with about $24 \%$ of adolescent girls getting pregnant before the age of 19(UDHS, 2011).

A 25\% pregnancy rate among adolescents in a population of 30 million people is therefore a worrying issue for the government of Uganda. In Uganda, early marriage and childbearing are encouraged through traditional, social, economic, and cultural norms. Therefore, cultural and social pressure from families of adolescents forces them to marry young and begin childbearing at an early age (UDHS, 2011).

Most teenagers start having sexual intercourse at a very early age. This predisposes them to teenage pregnancies especially when there is no use of contraception measures. Engaging in sexual relations at a young age is associated with low socioeconomic status or poverty among people. Lack of adolescent reproductive health education, school dropout due to lack of school fees, child-headed families due to HIV/AIDS scourge, and bad behaviour among unruly adolescents are particularly implicated. A study in Uganda showed that the age of sexual intercourse for females was 15.5 years and this was linked to teenage pregnancy and early childhood bearing (Mugabe, 2006).

The International Conference on Population and Development (ICPD) among other concerns put reproductive health and reproductive rights of young people as a concern. They urge governments in collaboration with civil society to take an initiative to meet the adolescent reproductive and sexual needs, so Uganda National Fund for Population Activities (UNFPA) through its staff, government officials, national and international advisory issued a program advisory note recommending greater attention to meeting the peoples' reproductive health needs and services (UDHS, 2006).

36.4 million Women aged 20 to 24 in 2010 had their first live birth before age 18, and about 5.6 million did so before 15 years. This value is equivalent to 7.3 million girls under the age of 18 giving birth every year, or 20,000 every day. Almost half (17.4 million) of the 36.4 million adolescent mothers lived in South Asia. Sub-Saharan Africa, with the highest prevalence of pregnancies among adolescent girls, accounted for $28 \%$ of adolescent mothers, with $15 \%$ in West and Central Africa, and 13 percent in Eastern and Southern Africa (UNFPA, 2013).

Every year about two million girls under the age of 15 and 16 million of girls aged 15 to 19 give birth. Globally, by the age of 18, one in five girls has given birth. This figure rises to over one in three girls in the poorest regions of the world. About $95 \%$ of all adolescent births occur in low- and middle-income countries. The poor, less educated and rural populations are more likely to have adolescent births within countries (WHO, 2014).

Teenage pregnancy is a big challenge to individuals, families, communities, and the nation as a whole. Approximately, third (1/3) of females who carry out induced abortions are teenagers (Mugabe, 2006).

A study done by UDHS, (2011), indicates that $13 \%$ of maternal deaths and $27.8 \%$ of deaths among adolescents in Uganda are primarily due to unsafe abortions. There are several policies in place to delay and protect adolescents from becoming pregnant like the National Health Policy, the National Adolescent Health Policy, the Minimum Age of Sexual Consent Policy (set at 18 years of age), the defilement law, etc. These policies help by fostering a supportive environment to encourage adolescent reproductive health.

In Uganda, the maternal mortality rate of $435 / 100,000$ mothers of which a large population of women dies from abortion complications in adolescents. Uganda also ranks high in the adolescent pregnancy rates in the sub - Saharan African countries. In the available data, most studied districts show that adolescents 
become pregnant at the age of 16-18 years. Teenagers are prone to getting complications like obstructed labour, post-partum haemorrhage, and vaginal tears due to inadequate birth canal and abortions. They lack knowledge of proper nutrition in pregnancy, the role of antenatal care visits, and parental care for the new born infant. These are the same people likely to produce and dump their children in latrines, streets, bushes, and dustbins (Massawe, 2007).

This may not be so different from what is happening in Mukono parish in Kanungu District since it contains a population accounted for in the rate mentioned above hence a reason for the study to be carried out in this specific parish.

Even though the Ugandan government has put efforts in advocating against teenage pregnancies through the ministry of health $(\mathrm{MoH})$, and ministry of education and sports for schooling adolescents and training health workers on the provision of adolescent-friendly health services, there is still a high incidence of teenagers getting pregnant and aborting leading to increased maternal mortality. However, the public seems to be less concerned about this problem. Therefore, results from this study will be used to assess the effectiveness of sexual education and other measures put in place by the government of Uganda and the non-governmental organizations (NGOs) to reduce the rate of teenage pregnancies. More so, it will enlighten policymakers, health planners, and other researchers about the possible measures towards approaching this problem, its causes, and its associated effects.

\section{Study design}

\section{METHODOLOGY}

A cross-sectional descriptive study design was used in this study. This was used because it yields results in a short time. The study will be focused on knowledge and effects of teenage pregnancies among adolescents aged 13 to 19 years in Mukono parish, Kanungu district. Data will be collected from February 10, 2016, to February 21, 2016, for ten days.

\section{Study site}

This study was carried out in Mukono parish located in Kayonza sub-county, Kanungu district South Western part of Uganda. Mukono parish is composed of 11 villages with a general population of about 8,356 people, 1,826 Households, and about 1,555 teenagers. Kanungu District is one of the hard to reach areas of Uganda due to the poor roads and lack of enough transport means to the area. One of the major activities carried out in the area is Tourism from Bwindi Impenetrable National park that occupies part of Mukono parish.

\section{Study population}

The study population consisted of adolescent females aged $13-19$ years old in Mukono parish Kayonza sub-county Kanungu District.

Study variables

\section{Independent variables}

These included gender, age, education status, tribe, marital status, religion, and occupation.

\section{Dependent variables}

These included the knowledge and effects of teenage pregnancies between 13 to 19 years.

\section{Sampling frame}

The study was focused on adolescents from 13 to 19 years who were obtained from the parish register book with the parish chief.

The list of names of students and pupils that fall in this category was used by the researcher to select teenagers that qualify for the study.

Sample size determination

The sample size was calculated using the formula below

$\mathbf{N}=\mathbf{Z 2} \mathbf{P}(\mathbf{1 - P}) / \mathbf{D} 2$ (Kish and Leslie, 1965).

Where $\mathrm{N}=$ minimum sample size

$\mathrm{Z}=\mathrm{a}$ standard normal deviate value that corresponds to a level of statistical significance equal to 1.96

$D=$ margin of error which corresponds to the level of precision of results desired $=5 \%$ 
$\mathrm{P}=$ estimate of the prevalence of teenage pregnancies in Uganda $25 \%$

$\mathrm{N}=(1.96) 2 \times 0.25 \times 1-0.25 / 0.0025$

Minimum sample size $=284$.

The sample size is 284 but due to limited time and financial resources, a sample size of 100 was used.

\section{Sampling method}

The researcher used a simple random sampling method; 10 days of the month was selected. The sample size of 100 divided equally among the ten selected days resulting in to10 respondents from each day. Each of the selected days had ten papers labeled YES and the rest NO. Each respondent who picked YES and who gave informed consent were interviewed. The same procedure was adopted in the 10 days until the end of the data collection.

\section{Pilot study}

A pilot study was conducted on ten adolescents in Kakinga village, Ishongororo sub-county Ibanda District to evaluate the feasibility, time, cost, and effect size in an attempt to predict an appropriate sample size and improve upon the study design before the performance of a full-scale research study. The results were analyzed but not included in the final study.

\section{Data collection}

Data was collected using a pre-tested questionnaire by the researcher basing on the study objectives. It was self-administered for literate respondents and the researcher administered for illiterate ones.

\section{Quality control}

To ensure that the right data was collected, the questionnaire was pre-tested on 10 adolescents to find out whether the questionnaire was easily understood and answered as required. Mistakes detected were corrected. Also, research assistants were trained to help in data collection.

\section{Data analysis and presentation}

Data were manually analyzed then presented in frequency distribution tables, pie-charts, statements, and bar graphs.

\section{Ethical consideration}

The researcher will obtain an introductory letter from Medicare Health Professionals College which will be addressed to the Mukono parish chief. The researcher will also explain to the parish chief what he would intend to do in particular and a copy of the questionnaire will be handed to him.

The researcher clearly explained to the respondents the aim and purpose of the study to gain their maximum co-operation. Respondents participated in the study after consent either verbally or by signature/thumbprints and the information is given remained confidential.

\section{Dissemination of study results}

The result of this study was disseminated to the following people: The Parish Chief Mukono parish, Uganda Allied Health Examination Board, the research committee Medicare Health Professionals College, and my research supervisor Mr. Joash Otieno Odiwuor. Also, the researcher remained with a copy of his research project.

\section{Results}

The data were collected within ten days and results got from 100 respondents and findings are presented below starting with the respondents' social demographic data, knowledge about teenage pregnancies, and effects on teenage pregnancies.

\section{Respondent characteristics}

Forty-four (44\%) of the respondents were aged between 16-18 years.

Thirty-eight (38\%) of the respondent were Bakiga, whereas 12 (12\%) were Banyarwanda.

Forty-two (42\%) of the respondent were Catholics, 31 (31\%) were Anglicans and 27 (27\%) others included Seventh Day Adventist and Moslems. 
Table 1. Shows characteristics of the respondents in terms of age, $n=100$

\begin{tabular}{lll}
\hline Age (years) & Frequency & Percentage (\%) \\
$13-15$ & 24 & 24 \\
$16-18$ & 44 & 44 \\
19 & 32 & 32 \\
Total & 100 & 100 \\
\hline
\end{tabular}

Table 2. Respondents by tribe, $n=100$

\begin{tabular}{lll}
\hline Tribe & Frequency & Percentage (\%) \\
Bakiga & 38 & 38 \\
Banyakole & 29 & 29 \\
Batwa & 21 & 21 \\
Banyarwanda & 12 & 12 \\
Total & $\mathbf{1 0 0}$ & $\mathbf{1 0 0}$ \\
\hline
\end{tabular}

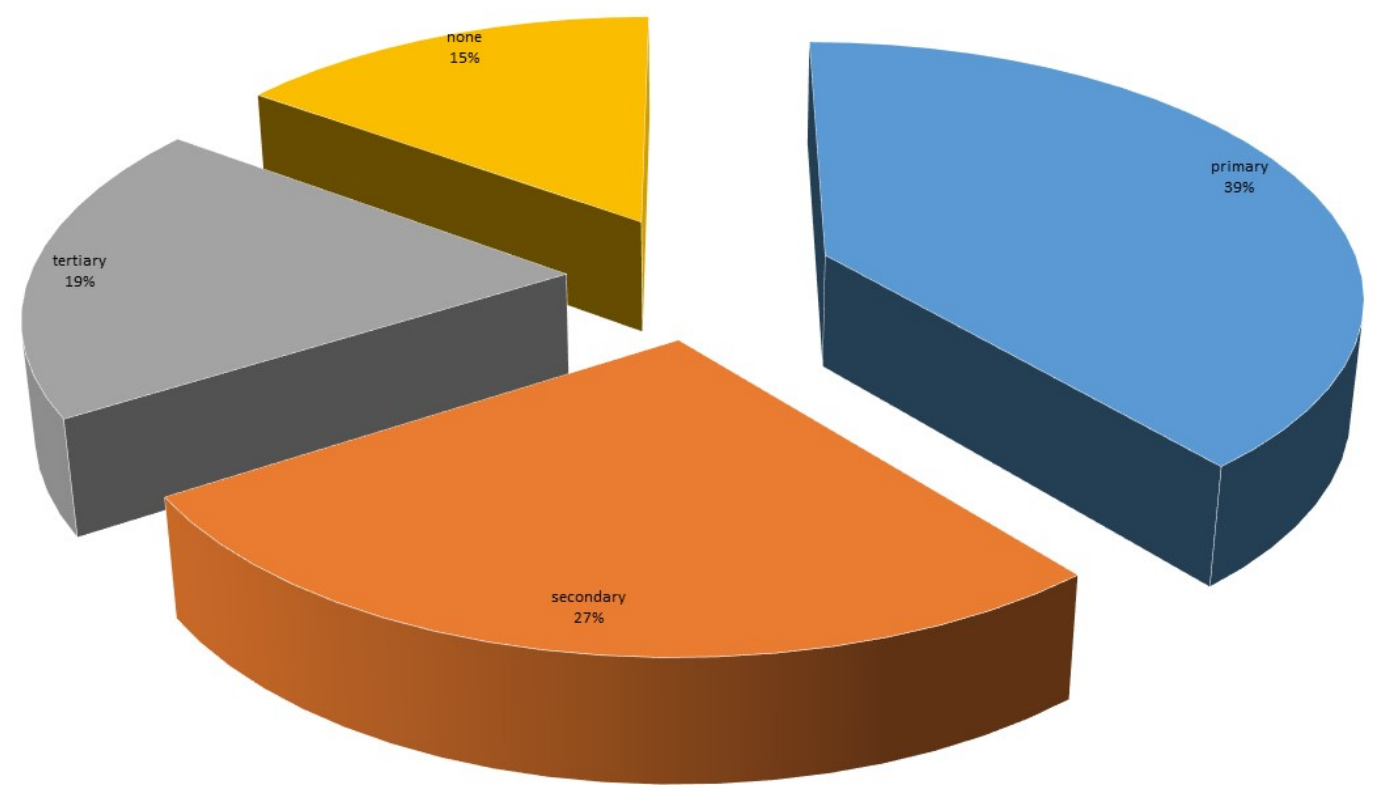

Chart 1. Shows characteristics of the respondents in terms of education level, $n=100$

Figure 1: Shows characteristics of the respondents in terms of education level, $n=100$

Thirty-nine (39\%) of the respondents had attended primary school whereas $15(15 \%)$ had not attended. Thirty-three (33\%) of the respondents were self-employed, 49 (49\%) employed by others whereas 18 (18\%) not employed.

Fifty-one (51\%) of the respondents were single whereas 15 (15\%) were married.

\subsection{Knowledge about teenage pregnancy}

Sixty (60\%) of the respondents believes that teenager is aged between13-19 years, whereas $10(10 \%)$ said15-20 years.

Figure 2: Distribution of respondents' by knowledge on sex education $n=100$ 
Table 3. Shows characteristics of the respondents in terms of marital status, $n=100$

\begin{tabular}{lll}
\hline Status & Frequency & Percentage (\%) \\
Married & 15 & 15 \\
Single & 51 & 51 \\
Divorced & 9 & 9 \\
Cohabiting & 25 & 25 \\
Total & $\mathbf{1 0 0}$ & $\mathbf{1 0 0}$ \\
\hline
\end{tabular}

Table 4. Distribution of respondent by meaning of teenager $n=100$

\begin{tabular}{lll}
\hline Response & Frequency & Percentage \\
$10-15$ & 25 & 25 \\
$13-19$ & 60 & 60 \\
$15-20$ & 10 & 10 \\
$16-24$ & 15 & 15 \\
Total & $\mathbf{1 0 0}$ & $\mathbf{1 0 0}$ \\
\hline
\end{tabular}

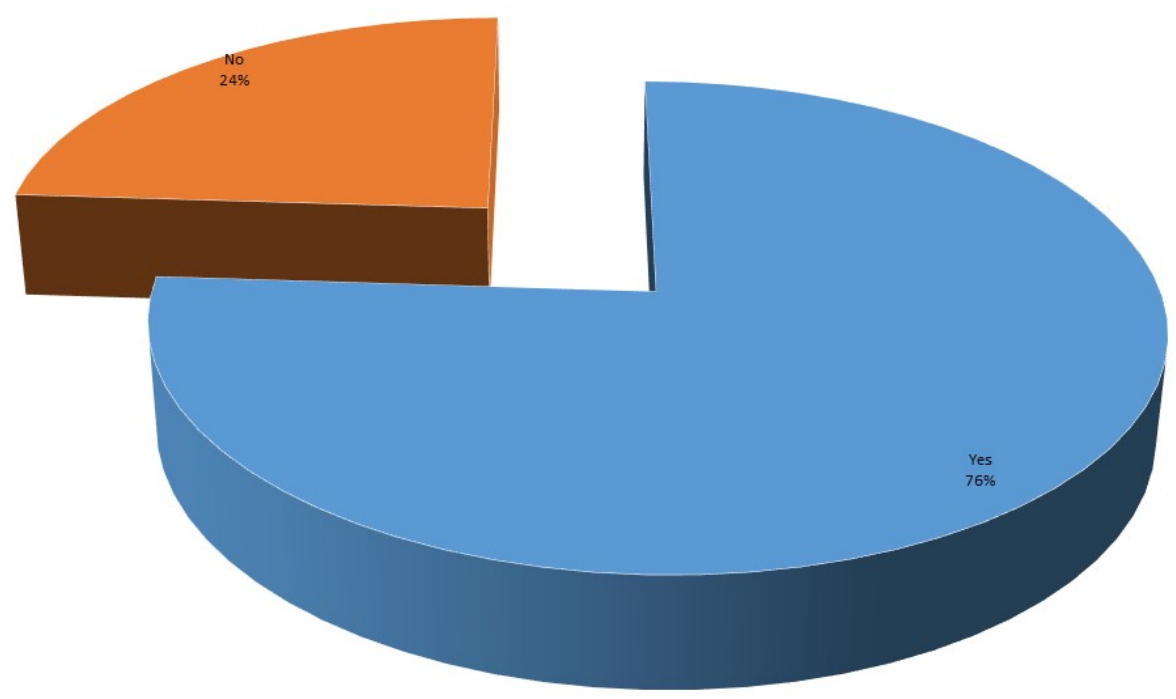

Chart 2. Distribution of respondents' by knowledge on sex education $n=100$

Seventy-six (76\%) of the respondent said they have ever had about sex education while 24 (24\%) had not.

Forty-two (42\%) of the respondent got information from a school teacher whereas 14 (14\%) from parents.

\subsection{Effects of teenage pregnancies}

Fifty-five (55\%) of the respondents believed that young mothers delivering a low birth weight baby is a physical effect of teenage pregnancy.

Fifty-three (53\%) of the respondents believed that girls fear carrying the pregnancy to term hence opts to abort is a psychological effect of teenage pregnancy. 
Table 5. distribution of respondents by source of the information $n=100$

\begin{tabular}{lll}
\hline Source of information & Frequency & Percentage \\
Parents & 14 & 14 \\
School teacher & 42 & 42 \\
Health worker & 16 & 16 \\
Newspaper (straight talk) & 28 & 28 \\
Total & $\mathbf{1 0 0}$ & $\mathbf{1 0 0}$ \\
\hline
\end{tabular}

Table 6. respondents by physical effects associated with teenage pregnancy $n=100$

\begin{tabular}{lll}
\hline Physical effect & Frequency & Percentage \\
Mother gets obstructed labour & 18 & 18 \\
Young mother delivers a low birth weight baby & 55 & 55 \\
Mother can get tears of birth canal at delivery & 17 & 17 \\
Don't know any physical effects & 10 & 10 \\
Total & $\mathbf{1 0 0}$ & $\mathbf{1 0 0}$ \\
\hline
\end{tabular}

Forty-five (45\%) of the respondents believed that school dropout is a social effect of teenage pregnancy.

Sixty-seven (67\%) of the respondent believed that the born infant often suffers malnutrition due to poverty effect of teenage pregnancy.

\section{DISCUSSION, CONCLUSIONS, AND RECOMMENDATION Respondent characteristics}

Most of the respondents $44 \%$ were aged between $16-18$ years, $32 \%$ were 19 years, and $24 \%$ were aged between 13-15 years.

Most of the respondents 38\% were Bakiga, 29\% Banyankole, 21\% Batwa and 12\% Banyarwanda

Most of the respondents $42 \%$ were Catholics, 31\% were Anglicans, and 27\% others included Seventh Day Adventists and Moslems.

Most of the respondents 39\% attended primary school, 27\% secondary, and 19\% tertiary whereas 15\% had not attended any formal education.

Most of the respondents $49 \%$ employed by others, $33 \%$ were self-employed whereas $18 \%$ not employed. The majority of the respondents $51 \%$ were single, 25\% cohabiting, 15\% married and $9 \%$ divorced

\section{Knowledge about teenage pregnancy}

Majority of the respondents $76 \%$ had prior knowledge about sex education whereas $24 \%$ had not. This can be attributed to their educational background as 39\% attended primary school, $27 \%$ secondary, $19 \%$ tertiary, and education plays an important role in shaping one's behaviour. This is in agreement with the study done by moses et al.,(2009) which reported that there is a strong association between the level of education attained and pregnancy.

Table 7. respondents by psychological effects associated with teenage pregnancy $n=100$

\begin{tabular}{lll}
\hline Psychological effect & Frequency & Percentage \\
Some girls fear carrying the pregnancy to term hence opts to abort & 53 & 53 \\
The mother is less likely to attend or receive antenatal care & 25 & 25 \\
The child of teen mother is more likely to grow up without the father & 12 & 12 \\
Don't know any of the psychological effects & 10 & 10 \\
Total & $\mathbf{1 0 0}$ & $\mathbf{1 0 0}$ \\
\hline
\end{tabular}


Table 8. Respondents by social effects associated with teenage pregnancy $n=100$

\begin{tabular}{lll}
\hline Social effect & Frequency & Percentage \\
Teen mother is mother is more likely to have no or low qualifications & 34 & 34 \\
School dropout & 45 & 45 \\
Child of teen mother is more likely to abuse drugs & 9 & 9 \\
Don't know any of the social effects & 12 & 12 \\
Total & $\mathbf{1 0 0}$ & $\mathbf{1 0 0}$ \\
\hline
\end{tabular}

Table 9. Respondents by economic effects associated with teenage pregnancy $n=100$

\begin{tabular}{lll}
\hline Economic effect & Frequency & Percentage \\
Born infant often suffer malnutrition due to poverty & 67 & 67 \\
Low productivity and unemployment & 21 & 21 \\
Don't know any of the economic effect & 12 & 12 \\
Total & $\mathbf{1 0 0}$ & $\mathbf{1 0 0}$ \\
\hline
\end{tabular}

Most of the respondents $42 \%$ got the information from the school a gesture that respondents took part in the classroom discussion about sexuality, 28\% from newspapers -straight talk, $16 \%$ health workers, and $14 \%$ from their parents. This is in disagreement with a report done by Susheela et al., (2009), the report indicated that sexual activities started shortly before the onset of puberty between 11 and 14 years of age while sexual knowledge was imparted between 14 and 17 years. Parents were the first source of sexual information for $65 \%$ of teenagers but the Ugandan school system is inadequate in educating school boys and girls about healthy sexuality. School children, therefore, rely on self-education from peers without adequate and professional guidance and counselling.

Most of the respondents $40 \%$ believed that girls who are orphans are more likely to become pregnant, $33 \%$ said girls engaging in a sexual relationship at an early age, $15 \%$ girls not in school, and $12 \%$ did not know the answer. Orphans are more likely not to be in a good financial state and lack of education leads girls to engage in a sexual relationship at an early age. This is in agreement with a study done by Moses 2009, which reported that most (59.0\%) pregnant adolescents had not even gone to primary level education. Contraceptive use is as low as $23 \%$ and $50 \%$ of the population marries before the age of 18 years.

\section{Effects of teenage pregnancies}

The majority of the respondents $55 \%$ believed that young mothers tend to deliver low birth weight babies, which will lead to long term health impact on both the mother and the infant, $18 \%$ would get obstructed labour and die, $17 \%$ said that the mothers can get tear of the birth canal at delivery. This is in line with the study done by UNICEF, (2008), indicating that pregnant teens face a higher risk of obstructed labour, which if Caesarean section is not available can cause an obstetric fistula, a tear in the birth canal that creates leakage of urine and/or faeces.

When asked about psychological effects, the majority of the respondents $53 \%$ said some teens fear carrying the pregnancy hence opts to abort, $25 \%$ said they are less likely to attend antenatal care, and $12 \%$ said the teen mother's child is more likely to grow up without the father. This is in line with a study done by WHO, (2014), which indicated that pregnant adolescents are more likely than adults to have unsafe abortions. Likewise, it is in line with a study done by UNICEF, (2015), that indicated that pregnant teens are less likely to receive prenatal care, often seeking it only in the third trimester, if at all, and grows up without a father.

Most of the respondents $45 \%$ believed that school dropout is a social effect of teenage pregnancy, $34 \%$ said that teen mother is more likely to have no or low qualifications, and $9 \%$ said that child of a teen mother is more likely to abuse drugs, $12 \%$ didn't know any of the social effects. This is in agreement with 
the study done by UNICEF, (2015), which indicated that the child of a teen mother is more likely to live in poverty, grow up without a father, become a victim of neglect or abuse and do less well at school, become involved in crime, abuse drugs, and alcohol.

The majority of the respondents $67 \%$ believe that the born infant often suffers malnutrition due to the poverty effect of teenage pregnancy, $21 \%$ said low productivity and unemployment, and 12\% didn't know any of the economic effects. This is in line with a study done by UNFPA, (2013) that reported that teenage pregnancy can lead to school drop-out and loss of education, and lack of acquisition of productive or employable skills. This in turn leads to low productivity, which in the long-term contributes to poverty.

\section{CONCLUSION}

From the study, it is evident that the majority of the respondents $76 \%$ had prior knowledge about sex education however there is still a lack of exposure of the teenagers to sex education as the minority $24 \%$ had not access.

First-person to educate the teenagers are the parent, from the study parents take the least $14 \%$ in educating their teenagers. This is attributed to parents and guardians getting embarrassed to talk about sex education, thus the whole load is left for the schoolteachers. Orphaned teenagers, girls who are in school, and those teenagers who get involved in sexual relationships tend to get pregnant.

As cited from the study, teenage pregnancy leads to babies born with low birth weight, which is associated with long-term health impact on the mother and the infant, mother may get obstructed labour or tear of the birth canal at delivery and die. The study cited school dropouts hence have no or low qualification and thus teen mothers are more likely to abuse drugs.

Due to pressure from parents and psychological torture, some teens fear carrying the pregnancy hence opt to abort as well as less likely to attend antenatal care and the teen mother's child is more likely to grow up without the father.

\section{RECOMMENDATION}

The government in conjunction with the development partners needs to include sex education in the school curriculum. The girl child needs to be educated on how to protect herself and avoid becoming a victim of teenage pregnancy.

Parents should not shy away from educating their children about sex education while they are still young, by so doing the teens grow knowing the consequences of early pregnancy.

Pregnant teenagers need to be encouraged to attend antenatal care as well as welcomed into society without stigmatization.

Further studies can investigate the boy child's knowledge about teenage pregnancy.

\section{ACKNOWLEDGEMENTS}

I acknowledge the support extended to me by my mentor, Mr. Otieno Joash Odiwuor, for having offered invaluable guidance during this research report development.

I also acknowledge the support from Bwindi Community Hospital, and I am greatly indebted to the study participants and research assistants who took part in the study.

\section{Limitations.}

Limited resources to carry out more research activities and since I was a student with limited funding.

\section{References}

1. Moses KBG. (2009). Risk factors of adolescent pregnancy, Kabale district. mak.ac.ug. https://www.ma k.ac.ug/documents/Makfiles/theses/Kyokwijuka_Moses.pdf

2. Racheal Jewkes, Caesar Vundule, Fidelia Maforah and Esme Jordaan. (2001). Relationship dynamics and teenage pregnancy in South Africa, social science and medicine volume 52. https://www.academ ia.edu/17856029/Relationship_dynamics_and_teenage_pregnancy_in_South_Africa

3. Susheela S. Ann M M. Bankole A. Forence M. Wulf D and Elena P. (2006). Report. Unintended pregnancy and induced abortions in Uganda. Guttmacher Institute. https://www.guttmacher.org/site s/default/files/pdfs/pubs/2006/11/27/UgandaUPIA.pdf 
4. Uganda Bureau of Statistics and ICF International Inc. (2012). Uganda Demographic and Health Survey, 2011. Kampala: UBOS and Calverton, Maryland: ICF International Inc. https://dhsprogram.co $\mathrm{m} / \mathrm{pubs} / \mathrm{pdf} / \mathrm{fr} 264 / \mathrm{fr} 264 . \mathrm{pdf}$

5. Uganda Bureau of Statistics and Macro International Inc. (2007). Uganda Demographic and Health Survey Report. 2006. Calverton, Maryland, USA: UBOS and Macro International Inc. https://www.dhs program.com/pubs/pdf/FR194/FR194.pdf

6. UNFPA. (2013). Adolescent pregnancy a review of the evidence, UNFPA. https://www.unfpa.org/sites/ default/files/pub-pdf/ADOLESCENT_PREGNANCY_UNFPA.pdf

7. UNICEF. (2015). Situation Analysis of Children in Uganda. UNICEF: https://www.unicef.org/uganda/m edia/1791/file

8. World Health Organization, (2004). Adolescent Pregnancies, Geneva, World Health Organization. Doi: 10665/42903/9241591455_eng.pdf.

9. World Health Organization, (2014). Adolescent pregnancy. Geneva, hrp. www.who.int/reproductiveh ealth 